\title{
Good outcomes in a patient with a Duret hemorrhage from an acute subdural hematoma
}

This article was published in the following Dove Press journal:

International Medical Case Reports Journal

27 January 2016

Number of times this article has been viewed

\section{Ha Son Nguyen \\ Ninh B Doan \\ Michael J Gelsomino \\ Saman Shabani \\ Wade M Mueller}

Department of Neurosurgery, Medical College of Wisconsin, Milwaukee, WI, USA
Correspondence: Ha Son Nguyen Department of Neurosurgery, Medical College of Wisconsin, 9200 West Wisconsin Ave, Milwaukee, WI 53226, USA

Tel + I 4I4805 5400

Email hsnguyen@mcw.edu
Background: Secondary brain stem injury is associated with transtentorial herniation, and manifests as "Duret" hemorrhages. Such an injury has been considered a terminal brain stem event with a high morbidity and mortality, sometimes discouraging continuation of care. However, there have been rare instances where patients have had reasonable recovery. We report another case, emphasizing that such an injury by itself should not deter aggressive measures, as good outcomes remain a possibility.

Case presentation: A 37-year-old male sustained a right subdural hematoma after a mechanical fall while intoxicated. He presented initially with a Glasgow Coma Scale 15. Three days later, he exhibited acute neurological deterioration to Glasgow Coma Scale 4, requiring intubation and mannitol. Repeat scan demonstrated enlarging right subdural hematoma with worsening shift; brain stem hemorrhage was noted at pontomesencephalic junction. Patient was immediately taken for subdural hematoma evacuation. The following day, patient was able to sluggishly follow commands in all four extremities. He had a short stay for inpatient rehabilitation and underwent autologous cranioplasty at 3 months. On examination, he was awake, alert, and oriented to self, time, and location; he exhibited dysarthric speech, right ptosis, but followed commands in all four extremities with no focal motor weakness.

Conclusion: In contrast to the common belief, patients suffering from a "Duret" hemorrhage can still have a good outcome. "Duret" hemorrhages may not represent a fatal injury. The finding from this paper suggests the finding of "Duret" hemorrhages on imaging should not deter aggressive measures especially in patients with lesions causing significant mass effects. Overall clinical status should drive surgical options and clinical course.

Keywords: Duret hemorrhage, brain stem hemorrhage, subdural hematoma

\section{Introduction}

Secondary brain stem injury is associated with herniation syndromes, and manifests as "Duret" hemorrhages. ${ }^{1}$ Such an injury has been regarded as a fatal brain stem event with a high morbidity and mortality, sometimes discouraging continuation of care. ${ }^{2-6}$ However, there have been rare instances where patients have had reasonable recovery. ${ }^{1,2,7-12}$ We report another case, emphasizing that such an injury by itself should not deter aggressive measures, as good outcomes remain a real possibility.

\section{Case presentation}

Patient is a 37-year-old male, history of hypertension, who sustained a mechanical fall while intoxicated. He presented initially with a Glasgow Coma Scale (GCS) 15. A computed tomography head demonstrated a right frontal contusion and right subdural 
hematoma ( $5 \mathrm{~mm}$ thickness, $5 \mathrm{~mm}$ midline shift). Three days later, patient exhibited acute neurological deterioration; on examination, patient did not open eyes to pain; left pupil was $3 \mathrm{~mm}$, nonreactive; right pupil was $2 \mathrm{~mm}$, sluggish; patient exhibited extensor posturing in all four extremities. Mannitol was given and patient was emergently intubated. Repeat scan demonstrated enlarging right subdural hematoma $(6 \mathrm{~mm}$ thickness) with worsening shift $(7.3 \mathrm{~mm})$; brain stem hemorrhage was noted at pontomesencephalic junction (Figure 1); the latter was not evident during initial imaging. Patient was immediately taken for subdural hematoma evacuation. On postoperative day 1 , patient was able to sluggishly follow commands in all four extremities. Patient was extubated on postoperative day 3. Patient eventually had a short stay for inpatient rehabilitation. He underwent autologous cranioplasty at 3 months. On examination, he was awake, alert, and oriented to self, time, and location; he exhibited dysarthric speech, right ptosis, but followed commands in all four extremities with no focal motor weakness.

\section{Discussion}

Traumatic brain stem hemorrhages may be grouped based on primary or secondary etiologies. ${ }^{12}$ Primary etiologies are commonly associated with the traumatic event, accompanied by diffuse supratentorial lesions, and frequently identified on initial imaging. Mechanisms include diffuse axonal injury from acceleration/deceleration, inertial injury at the midbrain due to the tentorium or clivus, and hyperextension of the cervical spine that contuses the lower brain stem. ${ }^{2,12}$

On the other hand, secondary etiologies are related to transtentorial herniation due to intractable intracranial hypertension, manifesting as "Duret" hemorrhages. There is a predisposition for involvement at the midline of the rostral pons and the ventral tegmentum of the midbrain. ${ }^{4}$ Other findings related to herniation are possible, including lesions in the contralateral cerebral peduncle and infarction along the distribution of the posterior cerebral artery. ${ }^{8}$ Differentiation between primary and secondary brain stem hemorrhage may be challenging since "Duret" hemorrhages may transpire within a half-hour after the initial trauma. ${ }^{8}$ The reported incidence of "Duret" hemorrhages is $5 \%-10 \%$ of all brain stem hemorrhages in prior radiological studies. ${ }^{4,8}$

The pathogenesis of "Duret" hemorrhages has been debated. When the brain stem is displaced inferiorly, the basilar artery and its paramedian pontine perforating vessels remain relatively fixed; this may cause the latter

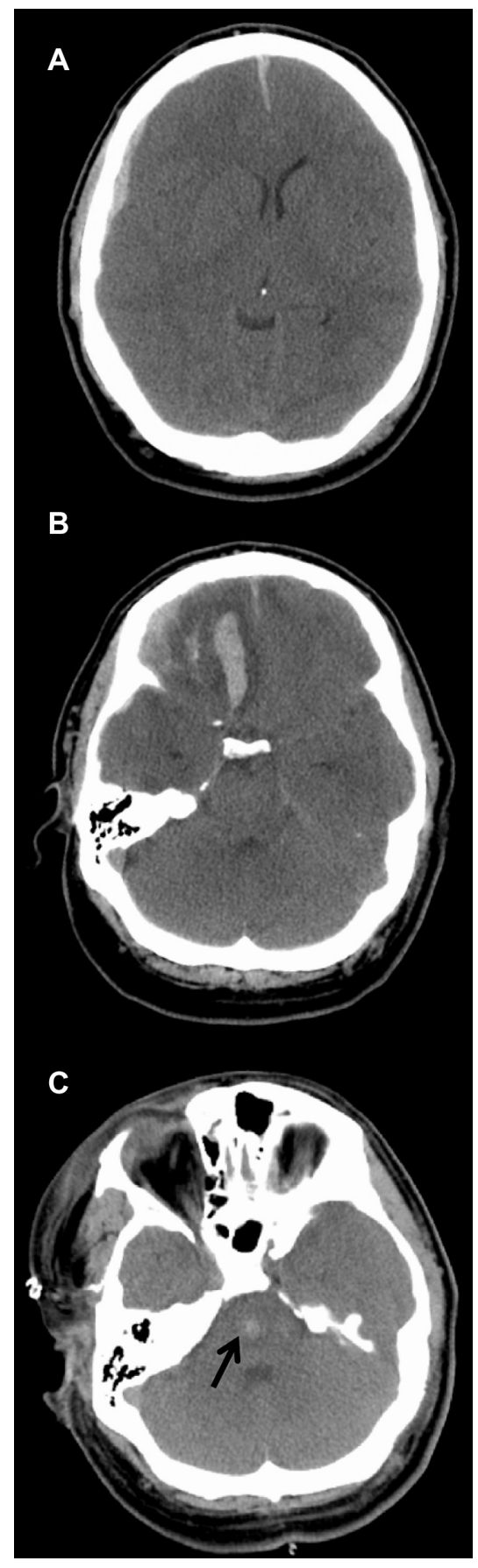

Figure I Computed tomography of the head after neurological deterioration: (A) right subdural hematoma, (B) right frontal contusion, and (C) "Duret" hemorrhage at the pontomesencephalic junction (arrow).

to shear and lead to hemorrhage. ${ }^{1,13}$ On the other hand, since veins are more compressible than arteries, herniation may lead to venous congestion and subsequent infarction at the rostal brain stem draining veins, followed by hemorrhagic conversion. ${ }^{1,13}$ Interestingly, an element of hemorrhage may be linked to reperfusion injury, as there have been reports of brain stem hemorrhages after surgical decompression..$^{7,9}$ 
"Duret" hemorrhage has been considered a fatal, irreversible brain stem event with high morbidity and mortality, sometimes discouraging continuation of care. ${ }^{2-6}$ However, early withdrawal of care eludes a true assessment of outcomes for such lesions. There have been rare instances in literature that document good functional outcomes. Table 1 provides a review of the available literature. Several authors believed that timely surgical decompression and/or early diagnosis may improve chances for good recovery. ${ }^{2,8,10,11}$ Ishizaka et $\mathrm{al}^{1}$ suggested that the overall, primary parenchymal injury may have a more significant influence on prognosis than Duret hemorrhages, where patients with Duret hemorrhages but relatively less primary injury may be salvageable. ${ }^{1,12}$ In addition, Beier and Dirks ${ }^{2}$ believed that a younger age (with inherent plasticity) could also be a factor for favorable prognosis.

The brain stem hemorrhage in our patient was consistent with a "Duret" hemorrhage; the finding was not evident during the initial imaging, where the patient had a good clinical examination after his traumatic event. Once the hematoma expanded and the shift worsened, the patient exhibited an acutely worsening neurological examination to GCS 4T, consistent with a herniation syndrome that likely led to the "Duret" hemorrhage. Based on the Brain Trauma Foundation guidelines, an acute subdural hematoma with midline shift greater than $5 \mathrm{~mm}$ prompts recommendation for surgical evacuation regardless of GCS. Fortunately, diagnosis and surgical decompression occurred at a timely manner. Though not as young as the pediatric patients reported by Beier and Dirks, ${ }^{2}$ the patient was relatively young. These factors likely facilitated a good recovery.

It is unclear what contributed to the patient's sluggishness after hematoma evacuation. An acute subdural hematoma that requires surgical evacuation is associated with many general neurocognitive morbidities. Moreover, the frontal lobe injury may also affect higher functions such as motivation, judgment, planning, and social behavior. In addition, the "Duret" hemorrhage may reflect injury at the reticular activating system, which also influences levels of consciousness. Given the favorable outcome, surgical interventions should remain an option for patients presenting with "Duret" hemorrhages and surgical lesions, such as a subdural hematoma, producing significant mass effect.

\section{Conclusion}

In contrast to the common belief, patients suffering from a "Duret" hemorrhage can still have good outcomes. "Duret"

Table I Review of literature

\begin{tabular}{|c|c|c|c|c|c|}
\hline Source & $\begin{array}{l}\text { Age } \\
\text { (years) }\end{array}$ & Sex & Mechanism & $\begin{array}{l}\text { Initial GCS } \\
\text { score }\end{array}$ & Outcome \\
\hline \multirow[t]{2}{*}{ Beier and Dirks ${ }^{2}$} & 5 & Male & Motor vehicle accident & 3 & $\begin{array}{l}\text { Residual left sixth and seventh } \\
\text { cranial nerve palsies } \\
\text { (Glasgow Outcome Scale 5) }\end{array}$ \\
\hline & 14 & Male & Fall down 20 stairs & 4 & $\begin{array}{l}\text { Only mild residual cognitive deficits } \\
\text { (Glasgow Outcome Scale 5) }\end{array}$ \\
\hline Fujimoto et al" & 44 & Female & $\begin{array}{l}\text { Craniotomy for CSF leak repair, } \\
\text { followed by epidural hematoma }\end{array}$ & $* * *$ & $\begin{array}{l}\text { Discharged with only confusion, } \\
\text { ocular bobbing, and bilateral } \\
\text { internuclear ophthalmoplegia }\end{array}$ \\
\hline Ishizaka et al' & 58 & Male & Spontaneous subdural hematoma & 5 & $\begin{array}{l}\text { Able to walk without assistance, } \\
\text { with persistent bilateral CN } 3 \text { palsy }\end{array}$ \\
\hline Kamijo et al ${ }^{10}$ & 30 & Male & $\begin{array}{l}\text { Hyponatremia leading to diffuse } \\
\text { cerebral swelling }\end{array}$ & $* * *$ & $\begin{array}{l}\text { Sodium level was corrected; he was } \\
\text { discharged from the hospital on day } \\
62 \text { with only slight left paresis }\end{array}$ \\
\hline Lonjaret et $\mathrm{al}^{7}$ & 21 & Male & Motor vehicle accident & 3 & $\begin{array}{l}\text { Persisted right fixed dilated pupil, } \\
\text { but fully conscious upon discharge } \\
\text { from intensive care }\end{array}$ \\
\hline Mathai et $\mathrm{al}^{12}$ & 21 & Male & Motorcycle accident & $* * *$ & $\begin{array}{l}\text { Delayed presentation with left facial } \\
\text { palsy and left hemiparesis, complete } \\
\text { recovery within } 6 \text { weeks }\end{array}$ \\
\hline Park et $\mathrm{al}^{9}$ & 76 & Male & $\begin{array}{l}\text { Status post bilateral burr holes for } \\
\text { chronic subdural hematoma }\end{array}$ & $* * *$ & Mild gait disturbance \\
\hline Stiver et $\mathrm{al}^{8}$ & 24 & Female & Motor vehicle accident & 6 & $\begin{array}{l}\text { Verbalizing appropriately in short } \\
\text { sentences, tolerating a normal diet, } \\
\text { and walking with minimal assistance. }\end{array}$ \\
\hline
\end{tabular}

Note: $* * *$ no available data.

Abbreviations: CN, cranial nerve; CSF, cerebrospinal fluid; GCS, Glasgow Coma Scale. 
hemorrhages may not represent a fatal injury. The finding from this paper suggests that the finding of "Duret" hemorrhages on imaging should not deter aggressive measures especially in patients with lesions causing significant mass effects. Overall clinical status should drive surgical options and clinical course.

\section{Acknowledgment}

Ethics approval and patient consent were not required by the Medical College of Wisconsin for this case report, as their ethics policy does not require approval or patient consent for case reports/series that involve less than three patients.

\section{Disclosure}

The authors report no conflicts of interest in this work.

\section{References}

1. Ishizaka S, Shimizu T, Ryu N. Dramatic recovery after severe descending transtentorial herniation-induced Duret haemorrhage: a case report and review of literature. Brain Inj. 2014;28:374-377.

2. Beier AD, Dirks PB. Pediatric brainstem hemorrhages after traumatic brain injury. J Neurosurg Pediatr. 2014;14:421-424.

3. Choi JH, Jakob M, Stapf C, Marshall RS, Hartmann A, Mast H. Multimodal early rehabilitation and predictors of outcome in survivors of severe traumatic brain injury. J Trauma. 2008;65:1028-1035.
4. Parizel PM, Makkat S, Jorens PG, et al. Brainstem hemorrhage in descending transtentorial herniation (Duret hemorrhage). Intensive Care Med. 2002;28:85-88.

5. Huddleston BJ, Sjostrom CM, Collins BT. Atypical teratoid/rhabdoid tumor involving cerebrospinal fluid: a case report. Acta Cytol. 2010;54:958-962.

6. Meyer CA, Mirvis SE, Wolf AL, Thompson RK, Gutierrez MA. Acute traumatic midbrain hemorrhage: experimental and clinical observations with CT. Radiology. 1991;179:813-818.

7. Lonjaret L, Ros M, Boetto S, Fourcade O, Geeraerts T. Brainstem hemorrhage following decompressive craniectomy. J Clin Neurosci. 2012;19:1293-1295.

8. Stiver SI, Gean AD, Manley GT. Survival with good outcome after cerebral herniation and Duret hemorrhage caused by traumatic brain injury. J Neurosurg. 2009;110:1242-1246.

9. Park KJ, Kang SH, Lee HK, Chung YG. Brain stem hemorrhage following burr hole drainage for chronic subdural hematoma - case report. Neurol Med Chir. 2009;49:594-597.

10. Kamijo Y, Soma K, Kishita R, Hamanaka S. Duret hemorrhage is not always suggestive of poor prognosis: a case of acute severe hyponatremia. Am J Emerg Med. 2005;23:908-910.

11. Fujimoto Y, Aguiar PH, Freitas AB, de Andrade AF, Marino Junior R. Recovery from Duret hemorrhage: a rare complication after craniotomy case report. Neurol Med Chir. 2000;40:508-510.

12. Mathai K, Jain A, Singh D, Dutta S, Sengupta SK, Harikrishnan V. The enigma of traumatic, behaviourally benign brain stem bleeds: case report. Ind J Neurotrauma. 2009;6:141-144.

13. Chew KL, BaberY, Iles L, O’Donnell C. Duret hemorrhage: demonstration of ruptured paramedian pontine branches of the basilar artery on minimally invasive, whole body postmortem CT angiography. Forensic Sci Med Pathol. 2012;8:436-440.
International Medical Case Reports Journal

\section{Publish your work in this journal}

The International Medical Case Reports Journal is an international, peer-reviewed open-access journal publishing original case reports from all medical specialties. Previously unpublished medical posters are also accepted relating to any area of clinical or preclinical science. Submissions should not normally exceed 2,000 words or

\section{Dovepress}

4 published pages including figures, diagrams and references. The manuscript management system is completely online and includes a very quick and fair peer-review system, which is all easy to use. Visit $\mathrm{http}: / /$ www.dovepress.com/testimonials.php to read real quotes from published authors. 